\title{
INFLUENCE OF POLYMER MOLECULAR WEIGHT ON LIGHT HARVESTING AND PERFORMANCE PARAMETERS OF THE ORGANIC SOLAR CELL
}

\author{
Yasser A. M. Ismail*, Naoki Kishi** and Tetsuo Soga** \\ Departments of "Third Generation Solar Cells Laboratory, Physics, Faculty of Science, Al-Azhar University, \\ Assiut 71121, Egypt and ${ }^{* *}$ Frontier Materials, Nagoya Institute of Technology, Nagoya 466-8555, Japan
}

\begin{abstract}
In the present article, we try to illustrate the behavior of the most common organic solar cell under the influence of polymer molecular weight (in the range of 21,100-128,800 g/mol) on light harvesting and device performance parameters. The present work demonstrates that, the molecular weight of donor polymer plays an important role in the light harvesting and performance of a common-bulk heterojunction organic solar cell based on poly(3-hexylthiophene) (P3HT), as a donor polymer, and [6,6]-phenyl-C $C_{61}$-butyric acid methyl ester (PCBM), as an acceptor. Through this study it is found that, the optical absorption of P3HT:PCBM solar cell active layer is increased by increasing P3HT molecular weight. This may be as a result of increasing active layer thickness and/or increasing backbone chain length of the polymer. In the same time, the absorption wavelength range is narrowed and the absorption peak position is shifted towards lower wavelengths due to the entanglement in polymer chains and reduction in polymer crystallinity at higher P3HT molecular weights. The external quantum efficiency (EQE) of the investigated solar cells is increased by increasing P3HT molecular weight until the molecular weight that entangles the P3HT chins and, therefore, restricts the charge carrier transfer and, then, reduces the EQE of the P3HT:PCBM solar cell. The performance parameters of the P3HT:PCBM solar cell are improved by increasing P3HT molecular weights around 25,300 g/mol and, after that, deteriorated at higher P3HT molecular weights up to $128,800 \mathrm{~g} / \mathrm{mol}$ as a result of polymer chain entanglement and reduction of the P3HT crystallinity. The present study shows that the best P3HT molecular weight is 25,300 g/mol, which produces power conversion efficiency around $2.5 \%$.
\end{abstract}

Keywords: Organic solar cells; Polymer molecular weight; Light harvesting; Device performance parameters

\section{INTRODUCTION}

Organic photovoltaic, the technology to convert sun light into electricity by employing thin films of organic semiconductors, has been the subject of active research over the past 2 decades and has received increased interest in recent years by the industrial sector [1]. Organic solar cells offer considerable promise for use in new solar energy technologies due to their flexible material properties and potential for low-cost manufacture [2]. Solar cells based on a bulk heterojunction of regioregular poly(3hexylthiophene) (P3HT) (which forms the holetransport network) and [6,6]-phenyl- $\mathrm{C}_{61}$-butyric acid methyl ester (PCBM) (which forms the electron-transport network) have been reported among the highest performing material systems to date and have been considered as the largest in researchers' investigations and studies [3-8] for improving their power conversion efficiencies. Beside improvements on the device side like thermal [4] or solvent annealing procedures, use of selective solvents [9], and solvent mixtures [10], an essential part came from continuous improvements in the material itself, i.e., reduction of synthetic impurities, higher regioregularities [11], and increased molecular weight [12-14].

P3HT is a semiconducting polymer which, in the last decade, has found widespread use in the general area of organic electronics and photonics in diverse applications such as polymer light emitting diodes [15], electro-chromic windows [16], nonlinear optical devices [17], batteries [18], artificial muscles [19], capacitors [20], organic field effect transistors [21], and organic photovoltaics [22]. Regioregular P3HT has emerged as a model polymer to investigate the relationship between macromolecular configuration, microstructure, and electronic properties. The molecular weight of polymer such as $\mathrm{P} 3 \mathrm{HT}$ plays a prominent role in its physical properties which can affect the performance parameters of a solar cell composed of the polymer as a donor and fullerene derivative as an acceptor. Indeed, depending on the regioregularity and molecular weight, $\mathrm{P} 3 \mathrm{HT}$ is a semi-crystalline polymer with a melting temperature of ca. $240{ }^{\circ} \mathrm{C}$ [23]. In addition, charge transport in P3HT has been found to display clear trends with molecular 
weight and whether the film displays one-phase (polycrystalline) or two-phase (entangled) morphologies. Previously, Kline et.al [24] have demonstrated that the field effect mobility of regioregular P3HT increases from $1.7 \times 10^{-6} \mathrm{~cm}^{2} / \mathrm{Vs}$ to $9.4 \times 10^{-3} \mathrm{~cm}^{2} / \mathrm{Vs}$ in field effect transistors as the molecular weight is increased from 3,200 to $31,100 \mathrm{~g} / \mathrm{mol}$. The molecular weight was found to affect the way chains pack on each other and thus causes the variation in the observed mobility. It is worthwhile to note that much of the improvement in device performance results from the increased crystallinity and charge carrier mobilities of the P3HT and fullerene phases which reduced charge carrier recombination losses $[11,25]$. Such influences of polymer molecular weight on polymer crystallinity, charge carrier mobilities, and solar cell morphology encourage us to investigate the effect of polymer molecular weight on optical absorption and performance parameters of the organic solar cell.

In the present work, the importance of polymer molecular weight for improving performance parameters of organic solar cells is illustrated. In addition, we try to construct a relationship between molecular weight of the materials used in solar cell active layer and the device performance parameters. Here, the effect of variation of polymer molecular weight, in the range from 21,100 to $128,800 \mathrm{~g} / \mathrm{mol}$, on optical absorption and performance parameters was investigated for the most common organic solar cell composed of $\mathrm{P} 3 \mathrm{HT}$ as a donor and PCBM as an acceptor. The indium-tin-oxide (ITO)/poly(3,4-ethylene dioxythiophene)-blend-poly(styrene sulfonate) (PEDOT:PSS)/P3HT:PCBM/Al bulk heterojunction solar cell was constructed with varying molecular weight of P3HT in the solar cell active layer. The optical absorption spectroscopy, photocurrent spectroscopy, and current density/ voltage $(\mathrm{J} / \mathrm{V})$ characteristics under AM1.5 white light illumination with an intensity of $100 \mathrm{~mW} /$ $\mathrm{cm}^{2}$ are investigated for the solar cells. The present study may increase our knowledge about the behavior of donor polymer under different molecular weights in the organic solar cell.

\section{EXPERIMENTAL PROCEDURES}

\subsection{Materials}

Regioregular P3HT (from Merck, Germany) and PCBM (from Nano Spectra, Japan) were purchased and used without further purification. Using 1,2-dichlorobenzene (Tokyo Chemical Industry Co. LTD, Japan) as a solvent, we prepared solution of the solar cell active layer through the blending of $\mathrm{P} 3 \mathrm{HT}$ at different molecular weights as $21100,25300,40000,51000$, and $128800 \mathrm{~g} /$ mol with the PCBM. The P3HT:PCBM blend had $1: 1$ weight ratio as a composition and 30 $\mathrm{mg} / \mathrm{mL}$ as a concentration. After blending P3HT with PCBM in amber glass bottles, the $\mathrm{N}_{2}$ gas was inserted for removing the oxygen with good sealing by Teflon tape. The blend solutions were vigorously stirred at $150 \mathrm{rpm}$ under $60{ }^{\circ} \mathrm{C}$ for more than $24 \mathrm{~h}$ outside glove box, and after that the blend solutions were further stirred for more than 4 days at room temperature under nitrogen atmosphere in a glove box to maximize mixing while avoiding touching the vial cap.

\subsection{FILM AND DEVICE FABRICATION}

For optical absorption measurement, the P3HT:PCBM blend films with different molecular weights of the $\mathrm{P} 3 \mathrm{HT}$ were prepared by spin-coating $(2000 \mathrm{rpm})$ the blend solutions onto clean ITO-glass substrates with thermal annealing using a digitally controlled hotplate at $110^{\circ} \mathrm{C}$ for 10 min under nitrogen atmosphere in a glove box. The film preparation and thermal annealing conditions were kept the same as those of the corresponding complete devices for accurate comparison.

For organic solar cell fabrication, the ITOglass substrates $\left(\sim 10 \Omega / \mathrm{cm}^{2}\right)$ were sequentially cleaned in an ultrasonic bath using acetone (twice) and methanol (once), rinsed with deionized water, and finally dried in flowing nitrogen. To increase the work function of the ITO electrode and to improve the electrical connection between ITO and organic active layer, a layer of PEDOT:PSS (Clavios) was spin-coated (2000 rpm) onto ITO-glass substrate in air and dried using a digitally controlled hotplate at 150 ${ }^{\circ} \mathrm{C}$ for $10 \mathrm{~min}$ under nitrogen atmosphere in a glove box. On top of the insoluble PEDOT:PSS layer, the P3HT:PCBM blend solutions, with different molecular weights of the P3HT, were spin-coated $(2000 \mathrm{rpm})$ and dried, for removing any residual solvent, at $110{ }^{\circ} \mathrm{C}$ for $10 \mathrm{~min}$ 
under nitrogen atmosphere in a glove box. An approximately 110-nm-thick Al electrode was thermally deposited onto the active layer using a vacuum deposition system at a pressure of about $3 \times 10^{-4} \mathrm{~Pa}$ through a shadow mask to obtain 25 identical cells on one device with an active area of $3 \times 3 \mathrm{~mm}^{2}$. Then, the devices were annealed in a nitrogen atmosphere at $140{ }^{\circ} \mathrm{C}$ for $4 \mathrm{~min}$ for increasing the electrical contact between solar cell active layer and $\mathrm{Al}$ electrode. The complete organic solar cells, with a configuration shown in Fig. 1, were stored in the dark under nitrogen atmosphere until measurements.

\subsection{MEASUREMENTS}

The optical absorption spectra of the P3HT: PCBM blend films with different molecular weights of the P3HT was measured using a JASCO V-570 ultraviolet/visible/near-infrared (UV/ vis/NIR) spectrophotometer. The optical light fell towards the coated side of the films using an ITO-glass substrate in the reference position. The external quantum efficiency measurement was performed for the devices using a halogen lamp and a monochromator. The J/V characteristics of the devices under white light illumination were determined using standard solar irradiation of $100 \mathrm{~mW} / \mathrm{cm}^{2}$ (AM1.5) with a JASCO CEP-25BX spectrophotometer $\mathrm{J} / \mathrm{V}$ measurement setup with a xenon lamp as the light source and a computer-controlled voltage-current source meter (Keithley 238) at $25{ }^{\circ} \mathrm{C}$ under nitrogen atmosphere. The J/V characteristics were determined for several cells in one device, and we considered the solar cell having the best performance parameters in that device. All measurements

Light

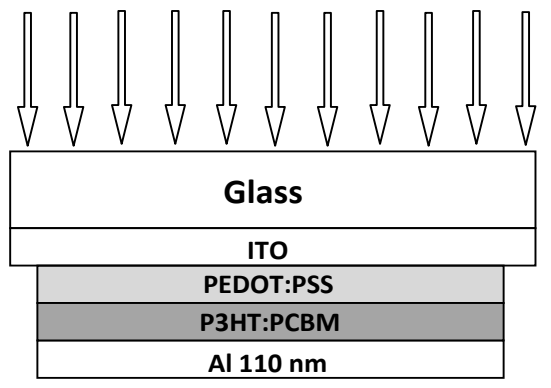

(a)

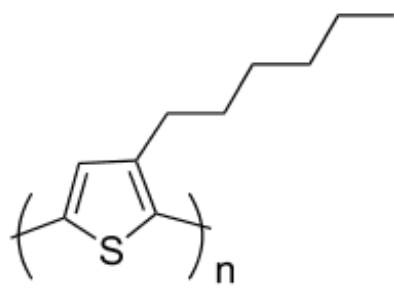

(b)

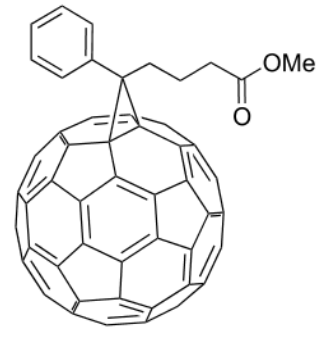

(c)

Fig. 1. (a) Cross-sectional view of P3HT:PCBM organic photovoltaic device and chemical structure of (b) P3HTand (c) PCBM. 
Yasser A. M. Ismail, et al.
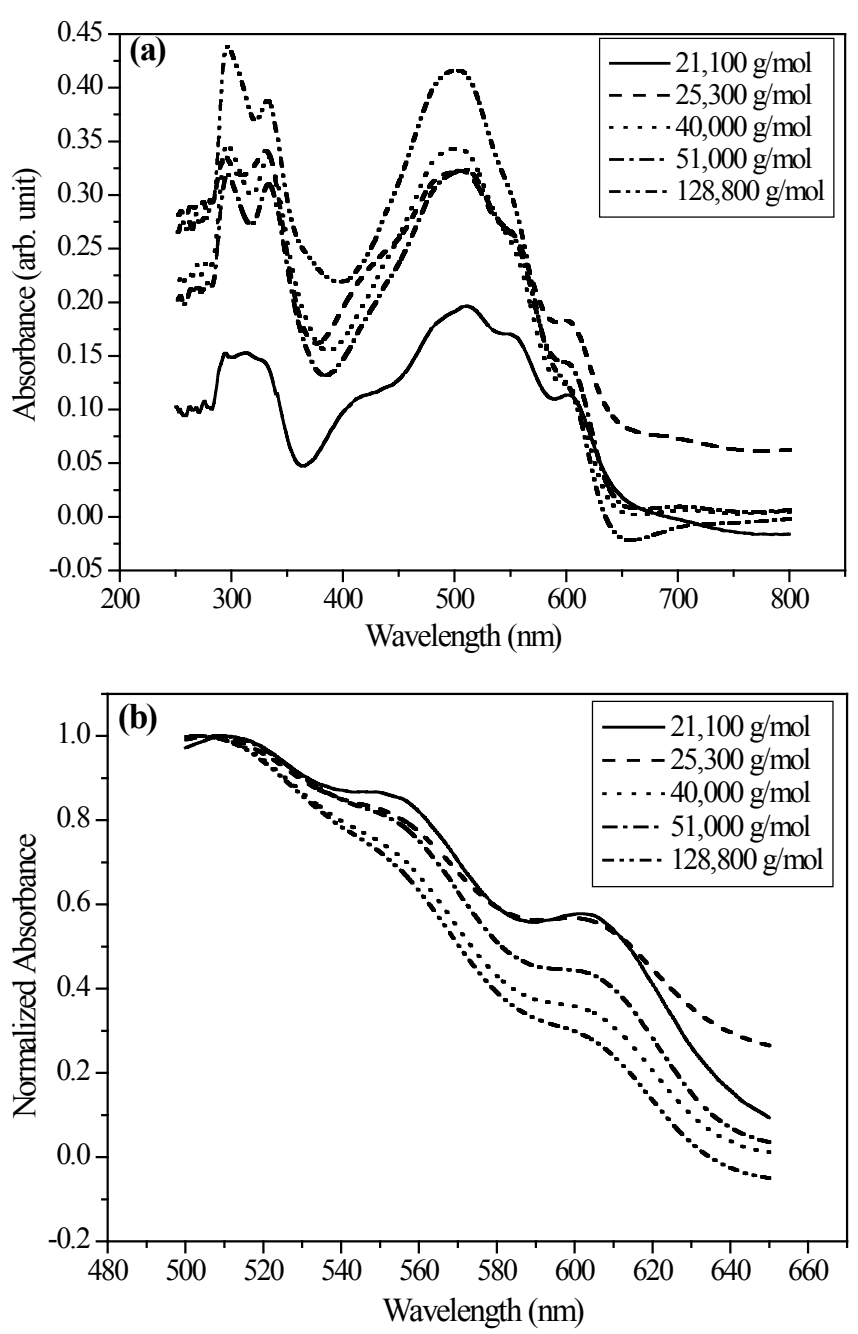

Fig. 2. (a) Optical absorption of P3HT:PCBM active layer with increasing P3HT molecular weight and (b) the shoulders area in the P3HT absorption spectrum at the wavelengths of 549 and $601 \mathrm{~nm}$.

tion peak value, (2) decrease in the absorption wavelength range, and (3) shift in the absorption peak towards lower wavelengths. As shown in Fig. 2(a), the increase in optical absorption peak value takes place from 0.2 to 0.42 (with about $52 \%$ increment) with increasing P3HT molecular weight from 21,100 to $128,800 \mathrm{~g} / \mathrm{mol}$, respectively.

The optical absorption spectroscopy is an efficient tool for detecting the organization of the molecules in crystalline domains as stated by Vanlaeke et al. [26]. The observed increase in the absorption peak value with increasing P3HT molecular weight may be attributed to the increase in film thickness due to the increase in the solution viscosity of the P3HT:PCBM blend. In general, the increase in molecular weight of polymers means the increase in the number of monomers (building units of the polymer) constituting the polymer. Therefore, the number and/or length of polymer chains will increase with increasing molecular weight of polymer. The increase in number of polymer chains tends to increase the density of entanglement points between polymer chains, and consequently the viscosity of the polymer will increase with increasing molecular weight of polymer. Koppe et al. [27] observed that the higher the molecular weight of P3HT the higher also is the viscosity, i.e., the density of entanglement points between polymer chains. Therefore, the viscosity of the P3HT:PCBM blend can increase with increasing P3HT molecular weight. Otherwise, the observed increase in the absorption peak value with increasing P3HT molecular weight can be accounted to the increase in the polymer backbone chain length which normally increases 
with increasing polymer molecular weight. By the increase in polymer backbone chain length, the number of absorbing organic groups in the polymer chain is increased, and, therefore, the absorption of the whole polymer increases at higher molecular weight. The observed narrowing in the absorption wavelength range by increasing P3HT molecular weight may be attributed to the increase in entanglement between P3HT chains, which tends to reduce the crystallinity of the polymer with increasing its molecular weight. In such a case, the microstructure of the P3HT in the blend film changes from chainextended crystals (at lower molecular weight) to a semicrystalline morphology where amorphous and crystalline domains are interconnected [28] with increasing P3HT molecular weight. The blue shift from 511 to $502 \mathrm{~nm}$ in P3HT absorption peak occurs with increasing $\mathrm{P} 3 \mathrm{HT}$ molecular weight from 21,100 to $128,800 \mathrm{~g} / \mathrm{mol}$, respectively, in the P3HT:PCBM solar cell active layer, as shown in Fig. 2(a). This blue shift is attributed to the increase in entanglement between P3HT chains, which tends to reduce the crystallinity of the polymer with increasing its molecular weight. The blue shift of the P3HT absorption peak occurring at higher molecular weight is an indication of decreasing conjugation length and crystallinity of the polymer. Depending on the observed blue shift in P3HT absorption peak, it can be concluded that the increase in P3HT molecular weight in the solar cell active layer tends to increase the energy gap of the P3HT polymer. However it can be observed from Fig. 2(a) that the increase in P3HT molecular weight does not shift the absorption of PCBM around the wavelength range 284- $384 \mathrm{~nm}$ in P3HT:PCBM blend films.

The suggested increase in chain entanglement and, subsequently, the decrease in crystallinity of P3HT with increasing its molecular weight can be proven through the decrease in vibronic structure of $\mathrm{P} 3 \mathrm{HT}$ polymer which can be observed through the decrease in the height of the shoulders appearing in the absorption spectra of the P3HT polymer around the wavelengths of 430, 549, and $601 \mathrm{~nm}$, as shown in Figs. 2(a) and 2(b). The vibronic structure is generally explained in semiconducting polymers by a higher crystallization or ordering of intra-chain interactions [29]. Specifically, low molecularweight polymers form crystalline domains of cofacially $\pi$-stacked molecules, while the usually entangled nature of higher molecular-weight polymers leads to microstructures comprised of molecularly ordered crystallites interconnected by amorphous regions. These amorphous regions may be the responsible for fluctuating the vibronic structure in the P3HT molecules in the P3HT:PCBM blend film.

3.2. Effect of P3HT molecular weight on external photocurrent quantum efficiency of the solar cell

The external quantum efficiency $(\mathrm{EQE})$ is defined as the ratio of the number of charges generated out of the device to the number of incident photons. The EQE spectra of the ITO/PEDOT: PSS/P3HT:PCBM/Al solar cells with varying P3HT molecular weight in the active layer blends are shown in Fig. 3 in the wavelength range from 300 to $800 \mathrm{~nm}$. The contribution of $\mathrm{P} 3 \mathrm{HT}$ to the photocurrent of the solar cells is observed in Fig. 3 around the wavelength of 490 $\mathrm{nm}$, where the P3HT has an absorption peak at $511 \mathrm{~nm}$, as shown in Fig. 2(a). Figure 3 shows an increase in the photocurrent of P3HT:PCBM solar cell with increase P3HT molecular weight up to $25,300 \mathrm{~g} / \mathrm{mol}$, and after that, the photocurrent decreases with further increasing P3HT molecular weight up to $128,800 \mathrm{~g} / \mathrm{mol}$. Generally, in organic solar cells, the EQE is affected not only by optical absorption but also by exciton dissociation, charge carrier transfer, and charge carrier collection at the electrodes. Therefore, the observed increase in EQE at lower P3HT molecular weights may be due to the improvement in light harvesting, as shown in Fig. 2(a), which can generate larger amount of the photocurrent, while the subsequent decrease in $\mathrm{EQE}$ is attributed to the chain entanglement of the $\mathrm{P} 3 \mathrm{HT}$ and the decrease in P3HT crystallinity at higher molecular weights which can restrict the charge carrier transfer through the solar cell active layer. Therefore, it can be concluded that the optical absorption plays prominent role for increasing EQE of the P3HT:PCBM solar cell only at lower P3HT molecular weights, while the chain entanglement and crystallinity of the P3HT play 
prominent role for decreasing EQE of the $\mathrm{P} 3 \mathrm{HT}$ : PCBM solar cell at higher P3HT molecular weights. Figure 3 shows a small contribution of PCBM to photocurrent of the P3HT:PCBM solar cell around the wavelength of $380 \mathrm{~nm}$, where the PCBM absorbs the light around the wavelength of $332 \mathrm{~nm}$, as shown in Fig. 2(a).

3.3. Effect of P3HT molecular weight on the performance parameters of the solar cell

In the present work, $\mathrm{J} / \mathrm{V}$ characteristics of the ITO/PEDOT:PSS/P3HT:PCBM/Al devices have been measured as a function of P3HT molecular weight in the solar cell active layer. From the analysis of the $\mathrm{J} / \mathrm{V}$ characteristics the photovoltaic performance parameters, i.e., open circuit voltage $\left(\mathrm{V}_{\mathrm{OC}}\right)$, short circuit current density $\left(\mathrm{J}_{\mathrm{SC}}\right)$, fill factor (FF), and power conversion efficiency (PCE), have been obtained for the investigated devices. Figures 4 and 5 show the variation of these parameters with increasing P3HT molecular weight in the solar cell active layer. Figure 4 shows an increase in $\mathrm{J}_{\mathrm{SC}}$ with increasing P3HT molecular weight up to $40,000 \mathrm{~g} / \mathrm{mol}$, while the $\mathrm{V}_{\mathrm{OC}}, \mathrm{FF}$, and, consequently, PCE are increased by increasing P3HT molecular weight up to $25,300 \mathrm{~g} / \mathrm{mol}$. After that, all devise performance parameters are decreased by increasing P3HT molecular weight up to $128,800 \mathrm{~g} / \mathrm{mol}$.

The observed increase in $\mathrm{J}_{\mathrm{SC}}$ may be attributed to the increase in optical absorption which is able to generate excess of charge carriers in the solar cell active layer. Actually, the optical absorption is not the solely responsible for affecting $\mathrm{J}_{\mathrm{SC}}$ that can be affected further by charge carrier transfer in the solar cell active layer. The charge carrier transfer in the present investigation seems to be deteriorated at higher P3HT molecular weights, at which the P3HT chains are entangled and/or the P3HT:PCBM film thickness is increased that results in reduction of charge carrier transfer in the solar cell active layer. Hence, the measured $\mathrm{J}_{\mathrm{SC}}$ is deteriorated as a result of deterioration of charge carrier transfer in the P3HT at higher molecular weights. The general perception in organic solar cells is that, the $\mathrm{V}_{\mathrm{OC}}$ is determined by the energy difference between the highest occupied molecular orbital (HOMO) of the donor and the lowest unoccupied molecular orbital (LUMO) of the acceptor [30]. Therefore, the possible reason of the observed increase in $\mathrm{V}_{\mathrm{OC}}$ is that the difference between $\mathrm{HOMO}$ of the donor polymer and LUMO of the acceptor PCBM increases with increasing P3HT molecular weight at 128,800 $\mathrm{g} / \mathrm{mol}$. This increase is as a result of increasing energy gap of the P3HT due to the increase in its molecular weight, according to the above arguments, and consequently, the $\mathrm{V}_{\mathrm{OC}}$ increases in the P3HT:PCBM solar cell.

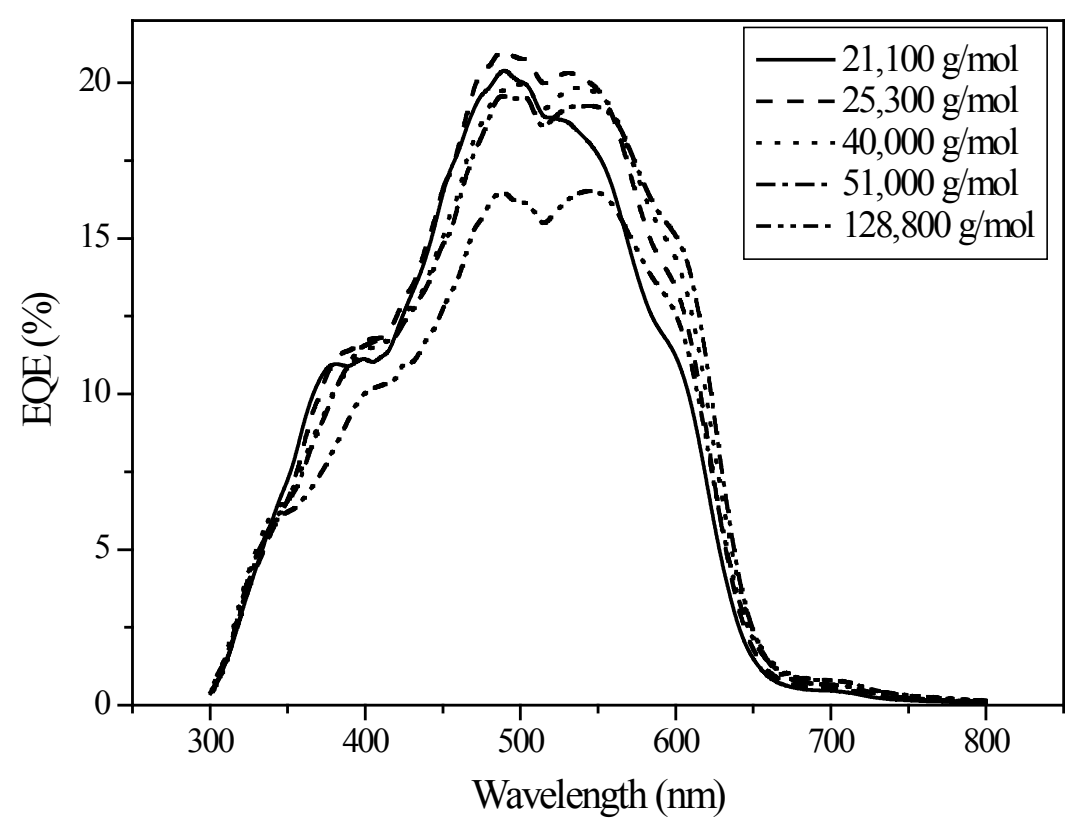

Fig. 3. EQE of the ITO/PEDOT:PSS/P3HT:PCBM/Al devices with varying P3HT molecular weight. 
The observed increase in FF with increasing P3HT molecular weight up to $25,300 \mathrm{~g} / \mathrm{mol}$, as shown in Fig. 5, is attributed to higher amount of charge carriers generated by optical absorption, which is affected by the increase in P3HT molecular weight up to $25,300 \mathrm{~g} / \mathrm{mol}$. While the following decrease in FF is attributed to the increase in polymer chain entanglement and/or increase in P3HT:PCBM film thickness, which increases with increasing P3HT molecular weight up to $182,800 \mathrm{~g} / \mathrm{mol}$. It is well known that, the increase in polymer chain entanglement and the increase in active layer thickness tend to increase the series resistance in solar cell active layer and, therefore, tend to decrease the FF of the solar cell. Depending on the previous measured device performance parameters, the PCE of the investigated solar cells can be shown in Fig. 5. From the data shown in Fig. 5, we can observe that the best P3HT:PCBM solar cell having higher PCE is that have $25,100 \mathrm{~g} / \mathrm{mol}$ as a molecular weight of the P3HT. This solar cell has PCE on the magnitude of $2.5 \%$.

\section{CONCLUSIONS}

As a conclusion, all the observed results in the present work demonstrate that, the molecular weight of donor polymer plays an important role in the performance of bulk heterojunction organic solar cells. It is found that, the increase in P3HT molecular weight in the solar cell active layer increases P3HT absorption peak value due to the increase in active layer thickness and/or due to the increase in polymer backbone chain length. In addition, the increase in P3HT molecular weight in P3HT:PCBM solar cell active layer can entangle the polymer chains and decrease the polymer crystallinity which is proven through the fluctuation of vibronic structure of the P3HT molecules at higher molecular weights. The suggested decrease in P3HT crystallinity tends to narrow the absorption wavelength range and tends to shift the absorption peak towards lower wavelengths. Through present investigations, it is observed that the increase in optical absorption of the P3HT:PCBM active layer (at lower P3HT molecular weights) tends to increase EQE, while the entanglement of the P3HT chains (at higher molecular weights) re- stricts charge carrier transfer and, then, reduces the EQE of the P3HT:PCBM solar cell. The effect of P3HT molecular weight on the device performance parameters showed that, the performance parameters of the P3HT:PCBM solar cell is improved at lower molecular weights around $25,300 \mathrm{~g} / \mathrm{mol}$. While the device performance parameters are deteriorated as a result of polymer chain entanglement and reduction of the crystallinity happening at higher P3HT molecular weights up to $128,800 \mathrm{~g} / \mathrm{mol}$. The present study showed that the best P3HT molecular weight is $25,300 \mathrm{~g} / \mathrm{mol}$, which produces power conversion efficiency with around $2.5 \%$.

\section{REFERENCES}

[1] B. Kippelen and J.-L. Brédas, Organic photovoltaics, Energy Environ. Sci. 2 (2009) 251-261.

[2] W. J. Belcher, K. I. Wagner, and P. C. Dastoor, The effect of porphyrin inclusion on the spectral response of ternary P3HT:porphyrin:PCBM bulk heterojunction solar cells, Sol. Energy Mater. Sol. Cells 91 (2007) 447-452.

[3] G. Yu, J. Gao, J. C. Hummelen, F. Wudl, and A. J. Heeger, Polymer photovoltaic cells: Enhanced efficiencies via a network of internal donor-acceptor heterojunctions, Science 270 (1995) 1789-1791.

[4] F. Padinger, R. S. Ritterberger, and N. S. Sariciftci, Effects of postproduction treatment on plastic solar cells, Adv. Funct. Mater. 13 (2003) 85-88.

[5] Y. Kim, S. Cook, S. M. Tuladhar, S. A. Choulis, J. Nelson, J. R. Durrant, D. D. C. Bradley, M. Giles, I. McCulloch, C. S. Ha, and M. Ree, A strong regioregularity effect in self-organizing conjugated polymer films and high-efficiency polythiophene:fullerene solar cells, Nat. Mater. 5 (2006) 197-203.

[6] J. Y. Kim, S. H. Kim, H.-H. Lee, K. Lee, W. Ma, X. Gong, and A. J. Heeger, New architecture for high-efficiency polymer photovoltaic cells using solution-based titanium oxide as an optical spacer, Adv. Mater. 18 (2006) 572-576.

[7] G. Li, V. Shrotriya, J. Huang, Y. Yao, T. Moriarty, K. Emery, and Y. Yang, High-efficiency solution processable polymer photovoltaic cells by self-organization of polymer blends, Nat. Mater. 4 (2005) 864-868.

[8] J. A. Hauch, P. Schilinsky, S. A. Choulis, R. Childers, M. Biele, and C. J. Brabec, Flexible organic P3HT: PCBM bulk-heterojunction modules with more than 1 year outdoor lifetime, Sol. Energy Mater. Sol. Cells 92 (2008) 727-731.

[9] S. E. Shaheen, C. J. Brabec, N. S. Sariciftci, F. Padinger, T. Fromherz, and J. C. Hummelen, 2.5\% efficient organic plastic solar cells, Appl. Phys. Lett. 78 (2001) 841-843. 
[10] Y. Yao, J. Hou, Z. Xu, G. Li, and Y. Yang, Effects of solvent mixtures on the nanoscale phase separation in polymer solar cells, Adv. Funct. Mater. 18 (2008) 17831789.

[11] H. Sirringhaus, P. J. Brown, R. H. Friend, M. M. Nielsen, K. Bechgaard, B. M. W. Langeveld-Voss, A. J. H. Spiering, R. A. J. Janssen, E. W. Meijer, P. Herwig, and D. M. de Leeuw, Two-dimensional charge transport in self-organized, high-mobility conjugated polymers, Nature (London) 401 (1999) 685-688.

[12] W. Ma, J. Y. Kim, K. Lee, and A. J. Heeger, Effect of the molecular weight of poly(3-hexylthiophene) on the morphology and performance of polymer bulk heterojunction solar cells, Macromol. Rapid Commun. 28 (2007) 1776-1780.

[13] P. Schilinsky, U. Asawapirom, U. Scherf, M. Biele, and C. J. Brabec, Influence of the Molecular Weight of Poly(3-hexylthiophene) on the Performance of Bulk Heterojunction Solar Cells, Chem. Mater. 17 (2005) 2175-2180.

[14] A. M. Ballantyne, L. Chen, J. Dane, T. Hammant, F. M. Braun, M. Heeney, W. Duffy, I. McCulloch, D. D. C. Bradley, and J. Nelson, The effect of poly(3-hexylthiophene) molecular weight on charge transport and the performance of polymer:fullerene solar cells, Adv. Funct. Mater. 18 (2008) 2373-2380.

[15] L.-W. Chonga, Y.-N. Choua, Y.-L. Leea, T.-C. Wena, and T.-F. Guo, Hole-injection enhancement of topemissive polymer light-emitting diodes by $\mathrm{P} 3 \mathrm{HT} /$ FNAB modification of Ag anode, Organic Electronics 10 (2009) 1141-1145.

[16] Y. Kim, Y. Kim, S. Kim, and E. Kim, Electrochromic diffraction from nanopatterned poly(3-hexylthiophene), ACS Nano 4 (2010) 5277-5284.

[17] X. Wang, J. Ru, S. Ochiai, Y. Yamada, Y. Ucihda, H. Furuhashi, T. Mizutani, Y. Cui, and J. Liu, Thickness dependence of third-harmonic generation from selfassembled regioregular poly(3-hexylthiophene) thin films on quartz glasses with different surfaces, Journal of Nonlinear Optical Physics \& Materials 17 (2008) 451-463.

[18] A. E. Javier, S. N. Patel, D. T. Hallinan Jr., V. Srinivasan, and N. P. Balsara, Simultaneous electronic and ionic conduction in a block copolymer: application in lithium battery electrodes, Angewandte Chemie-International Edition 50 (2011) 9848-9851.

[19] K. Y. Lee, B. Kumar, J.-S. Seo, K.-H. Kim, J. I. Sohn, S. N. Cha, D. Choi, Z. L. Wang, and S.-W. Kim, p-Type polymer-hybridized high-performance piezoelectric nanogenerators, Nano Letters 12 (2012) 1959-1964.

[20] Y. Z. Wang, Q. Wang, H. Y. Xie, L. P. Ho, D. M. Tan, Y. Y. Diao, W. Chen, and X. N. Xie, Fabrication of highly ordered P3HT:PCBM nanostructures and its application as a supercapacitive electrode, Nanoscale 4 (2012) 3725-3728.

[21] J. G. Labram, E. B. Domingo, N. Stingelin, D. D. C. Bradley, and T. D. Anthopoulos, In-situ monitoring of the solid-state microstructure evolution of polymer: fullerene blend films using field-effect transistors, Advanced Functional Materials 21 (2011) 356-363.

[22] G. Bernardo, and D. G. Bucknall, Recent progress in the understanding and manipulation of morphology in polymer:fullerene photovoltaic cells, in Optoelectronics, In-Tech Publications, (2013).

[23] J. Zhao, A. Swinnen, G. V. Assche, J. Manca, D. Vanderzande, and B. V. Mele, Phase diagram of P3HT/ PCBM blends and its implication for the stability of morphology, Journal of Physical Chemistry B 113 (2009) 1587-1591.

[24] R. J. Kline, M. D. McGehee, E. N. Kadnikova, J. Liu, and J. M. J. Frechet, Controlling the field $\square$ effect mobility of regioregular polythiophene by changing the molecular weight, Adv. Mater. (Weinheim, Ger.) 15 (2003) 1519-1522.

[25] C. Goh, R. J. Kline, M. D. McGehee, E. N. Kadnikova, and J. M. J. Frechet, Molecular-weight-dependent mobilities in regioregular poly (3-hexyl-thiophene) diodes, Appl. Phys. Lett. 86 (2005) 122110-122110/3.

[26] P. Vanlaeke, A. Swinnen, I. Haeldermans, G. Vanhoyland, T. Aernouts, D. Cheyns, C. Deibel, J. D'Haen, P. Heremans, J. Poortmans, and J. V. Manc, P3HT/PCBM bulk heterojunction solar cells: Relation between morphology and electro-optical characteristics, Sol. Energy Mater. Sol. Cells 90 (2006) 2150-2158.

[27] M. Koppe, C. J. Brabec, S. Heiml, A. Schausberger, W. Duffy, M. Heeney, and Iain McCulloch, Influence of molecular weight distribution on the gelation of P3HT and its impact on the photovoltaic performance, Macromolecules 42 (2009) 4661-4666.

[28] O. G. Reid, J. A. N. Malik, G. Latini, S. Dayal, N. Kopidakis, C. Silva, N. Stingelin, and G. Rumbles, The influence of solid-state microstructure on the origin and yield of long-lived photogenerated charge in neat semiconducting polymers, J. Polym. Sci. Pt. B-Polym. Phys. 50 (2012) 27-37.

[29] X. Jiang, R. Osterbacka, O. J. Korovyanko, C. P. An, B. Horowitz, R. A. J. Janssen, and Z. V. Vardeny, Spectroscopic studies of photoexcitations in regioregular and regiorandom polythiophene films, Adv. Funct. Mater. 12 (2002) 587-597.

[30] T. Yamanari, T. Taima, J. Sakai, and K. Saito, Origin of the open-circuit voltage of organic thin-film solar cells based on conjugated polymers, Sol. Energy Mater. Sol. Cells 93 (2009) 759-761. 